\title{
THE SUM TWO REFLECTIVE POLYNOMIALS AND ITS LINK WITH THE PROOF OF THE RIEMANN HYPOTHESIS
}

\author{
${ }^{1}$ Mathew Curtis and ${ }^{2}$ Gurudeo Anand Tularam \\ ${ }^{1}$ Department of Science Environment Engineering and Technology (BPS), \\ ${ }^{2}$ Department of Mathematics-Science Environment Engineering and Technology (ENV), \\ Environmental Futures Centre, Griffith University, Nathan Campus Queensland, 4111, Australia
}

Received 2013-06-29; Revised 2013-09-16; Accepted 2014-02-08

\begin{abstract}
The investigation into the summation of two polynomials of the same degree under special given conditions results in a polynomial whose solutions follow a pattern that can be easily predicted. In this study, the theory of such polynomials is developed for examination of the integral parts of Riemann's works. The analysis leads to a theorem that governs the solutions under certain conditions and applying this theorem to the expanded form of the Riemann-Eta function generates expressions that show why the Riemann hypothesis may be true.
\end{abstract}

Keywords: Polynomial, Riemann-Eta Function, Riemann Hypothesis

\section{INTRODUCTION}

The use of polynomials within algebraic mathematics has a long history dating back through the ages. Egypt, Babylon and India are a few countries where mathematicians had developed and solved algebraic equations such as linear and quadratic polynomials at an early stage (Tularam, 2011; 2013). A polynomial is an algebraic expression consisting of a number of terms that are made up from the product of a constant and a variable that is raised to a power of a whole number:

$$
\begin{aligned}
& f(x)=C_{n} x^{n}+C_{n-1} x^{n-1}+C_{n-2} x^{n-2} \\
& +\cdots+C_{2} x^{2}+C_{1} x+C_{0}=\sum_{i=0}^{n} C_{i} x^{i}
\end{aligned}
$$

The act of reflecting a polynomial function about the $\mathrm{y}$-axis is simply done by replacing $\mathrm{x}$ with $-\mathrm{x}$ :

$$
f(x)=f(-x)
$$

Solving a polynomial requires finding the values of the variables that resolve the polynomial to zero:

$$
f(x)=\sum_{i=0}^{n} C_{i} x^{i}=0
$$

The degree of a polynomial is used to describe a polynomial. The term within the polynomial with the highest power is considered the leading term and its power is the degree of the polynomial. The fundamental theorem of algebra states that a polynomial of degree $n$ has at most $n$ number of solutions when the polynomial is resolved to zero if all real, complex and repeated solutions are considered (Brenner and Lyndon, 1981). These solutions are called roots and can consist of both real and complex numbers and can be degenerate as stated previously. There exist formulas to solve linear (first order) and quadratic (second order) equations. Theories to solve polynomials of a higher degree exist but the known forms greatly increase in complexity as the degree increases. In 1824 however, a Norwegian mathematician, Niels Henrik Abel showed that there can be no finite formula involving only arithmetic operations and radicals for solving polynomials of degree five or higher (Agarwal et al., 2012). This shows that solving polynomials of higher degrees have been rather problematic for even the greatest of mathematicians. While finding the Corresponding Author: Gurudeo Anand Tularam, Department of Mathematics-Science Environment Engineering and Technology (ENV), Environmental Futures Centre, Griffith University, Queensland, 4111, Australia Tel: 61737353522, Fax: 61737357459 
roots of a polynomial can be complicated, this study suggests that there is an elegance and simplicity in the solutions to certain types of polynomials that are developed through the addition of two polynomials under special set of conditions. In this study, the application of the theory of such polynomials is found within the famously unsolved question known as the Riemann hypothesis. The Riemann hypothesis has plagued the mathematics community for over a century. It deals with the distribution of solutions of the Euler-Riemann Zeta function. The Euler-Riemann Zeta function is a function of the complex variable $\mathrm{s}$ that analytically deals with the sum of the infinite series $\sum_{n=1}^{\infty} \frac{1}{n^{s}}$. The Riemann hypothesis states that all non-trivial solutions to the Euler-Riemann Zeta function have the real part of (Titchmarsh, 1986; Edwards, 2001; Curtis and Tularam, 2011).

While history has shown many insights into how the solutions to the Zeta function work, researchers have yet to find a definitive answer as why the Zeta function solutions should act as conjectured by Riemann. The theorem governing operations on two polynomials can be used to describe the Zeta functions solutions in a fundamental manner. A detailed explanation will be provided in the following sections. An indication of where this idea arises can be noted in Fig. 1.

\subsection{Definitions and Notation}

This section provides definitions and description of the variables, terms and elements used in this study. The polynomials used in the investigation throughout this study are defined as follows.

Assuming 1 and $\mathrm{m}$ to be real numbers and allow two polynomials to be expressed in the following form:

$$
\begin{aligned}
& \mathrm{p}(\mathrm{x})=\left(\mathrm{x}-\mathrm{l}_{1}\right)\left(\mathrm{x}-\mathrm{l}_{2}\right)\left(\mathrm{x}-\mathrm{l}_{3}\right) \cdots\left(\mathrm{x}-\mathrm{l}_{\mathrm{n}}\right)=\prod_{\mathrm{j}=1}^{\mathrm{n}}\left(\mathrm{x}-\mathrm{l}_{\mathrm{j}}\right), \\
& \mathrm{q}(\mathrm{x})=\left(\mathrm{x}+\mathrm{m}_{1}\right)\left(\mathrm{x}+\mathrm{m}_{2}\right)\left(\mathrm{x}+\mathrm{m}_{3}\right) \cdots\left(\mathrm{x}+\mathrm{m}_{\mathrm{n}}\right) \\
& =\prod_{\mathrm{j}=1}^{\mathrm{n}}\left(\mathrm{x}+\mathrm{m}_{\mathrm{j}}\right), \mathrm{w}(\mathrm{x})=\mathrm{p}(\mathrm{x})+\mathrm{q}(\mathrm{x})
\end{aligned}
$$

The function $\mathrm{w}(\mathrm{x})$ is simply the addition of $\mathrm{p}(\mathrm{x})$ and $\mathrm{q}(\mathrm{x})$ and so is itself a polynomial. The solutions to $\mathrm{p}(\mathrm{x})=$ 0 occur when $x=-l_{j}($ where $j=1,2,3,4, \ldots, n)$; and the solutions to $q(x)=0$ occur when $x=-m_{j}$ (where $j=$ $1,2,3,4, \ldots, n)$. Assuming that the following set of conditions:

$$
1_{j}>0, \quad j=1,2,3,4, \cdots, n ; m_{j}>0, \quad j=1,2,3,4, \cdots, n ;
$$

$$
\begin{aligned}
& \left|1_{j}\right|<\left|1_{j+1}\right|, \quad j=1,2,3,4, \cdots, n-1 \\
& \left|m_{j}\right|<\left|m_{j+1}\right|, \quad j=1,2,3,4, \cdots, n-1 ;
\end{aligned}
$$

where the polynomial $q(x)$ is defined to be the reflected form of the polynomial $\mathrm{p}(\mathrm{x})$ about an axis of symmetry that occurs parallel to the $y$ axis. The axis of symmetry for $\mathrm{p}(\mathrm{x})$ and $\mathrm{q}(\mathrm{x})$ is $\mathrm{x}=\mathrm{x}_{\mathrm{s}}$ and is governed by: $-\mathrm{m}_{1}<\mathrm{x}_{\mathrm{s}}<$ $l_{1}$ where $-l_{1}$ and $-m_{1}$ are the first solutions to $\mathrm{p}(\mathrm{x})=0$ and $\mathrm{q}(\mathrm{x})=0$ respectfully. If $\mathrm{p}(\mathrm{x})$ and $\mathrm{q}(\mathrm{x})$ are reflected polynomials and if $h$ represents the shift that $q(x)$ undergoes after it is reflected on the vertical axis then the following is true:

$$
q(x)=p((-x)+2 h)=p(-(x-2 h))
$$

A special case exists when $\mathrm{h}=0$ and since $\mathrm{x}_{\mathrm{s}}=0$ as well, the axis of symmetry is the $y$ axis itself. For all cases $\mathrm{h}=\mathrm{x}_{\mathrm{s}}$ Equation (1):

$\mathrm{q}(\mathrm{x})=\mathrm{p}\left(-\left(\mathrm{x}-2 \mathrm{x}_{\mathrm{s}}\right)\right)$

Cases other than $\mathrm{h}=0$ will be considered in the following sections.

\subsection{Development of Theorem 1: Addition of two Polynomials}

The addition of two polynomials will result in a polynomial whose solutions can be partially predicted if the original polynomials follow the conditions stated in the previous section.

Figure 2 shows an example of the case of two polynomials of the form $q(x)$ and $p(x)$. It should be noted that the two polynomials will intersect at the axis of symmetry (defined by the dashed line). The point of intersection is defined to be $S$ (this occurs when $x=x_{s}$ ): $\mathrm{p}\left(\mathrm{x}_{\mathrm{s}}\right)=\mathrm{q}\left(\mathrm{x}_{\mathrm{s}}\right)$.

$\therefore \mathrm{w}\left(\mathrm{x}_{\mathrm{s}}\right)=\mathrm{p}\left(\mathrm{x}_{\mathrm{s}}\right)+\mathrm{q}\left(\mathrm{x}_{\mathrm{s}}\right)=2 \mathrm{p}\left(\mathrm{x}_{\mathrm{s}}\right)$; the point will be conjectured to be the minimum value of the singular turning point of the resulting polynomial $(\mathrm{w}(\mathrm{x}))$.

The values $\mathrm{w}(\mathrm{x})$ at a distance $\mathrm{d}$ from the $\mathrm{y}$ axis can be represented as $w\left(x_{s}+d\right)$ : i.e.:

$\mathrm{w}\left(\mathrm{x}_{\mathrm{s}}+\mathrm{d}\right)=\mathrm{p}\left(\mathrm{x}_{\mathrm{s}}+\mathrm{d}\right)+\mathrm{q}\left(\mathrm{x}_{\mathrm{s}}+\mathrm{d}\right)$.

Also, if:

- $\mathrm{p}\left(\mathrm{x}_{\mathrm{s}}+\mathrm{d}\right)+\mathrm{q}\left(\mathrm{x}_{\mathrm{s}}+\mathrm{d}\right)=2 \mathrm{p}\left(\mathrm{x}_{\mathrm{s}}\right)$ then $\mathrm{w}\left(\mathrm{x}_{\mathrm{s}}+\mathrm{d}\right)=\mathrm{w}\left(\mathrm{x}_{\mathrm{s}}\right)$

- $\mathrm{p}\left(\mathrm{x}_{\mathrm{s}}+\mathrm{d}\right)+\mathrm{q}\left(\mathrm{x}_{\mathrm{s}}+\mathrm{d}\right)<2 \mathrm{p}\left(\mathrm{x}_{\mathrm{s}}\right)$ then $\mathrm{w}\left(\mathrm{x}_{\mathrm{s}}+\mathrm{d}\right)<\mathrm{w}\left(\mathrm{x}_{\mathrm{s}}\right)$

- $\mathrm{p}\left(\mathrm{x}_{\mathrm{s}}+\mathrm{d}\right)+\mathrm{q}\left(\mathrm{x}_{\mathrm{s}}+\mathrm{d}\right)>2 \mathrm{p}\left(\mathrm{x}_{\mathrm{s}}\right)$ then $\mathrm{w}\left(\mathrm{x}_{\mathrm{s}}+\mathrm{d}\right)>\mathrm{w}\left(\mathrm{x}_{\mathrm{s}}\right)$ 


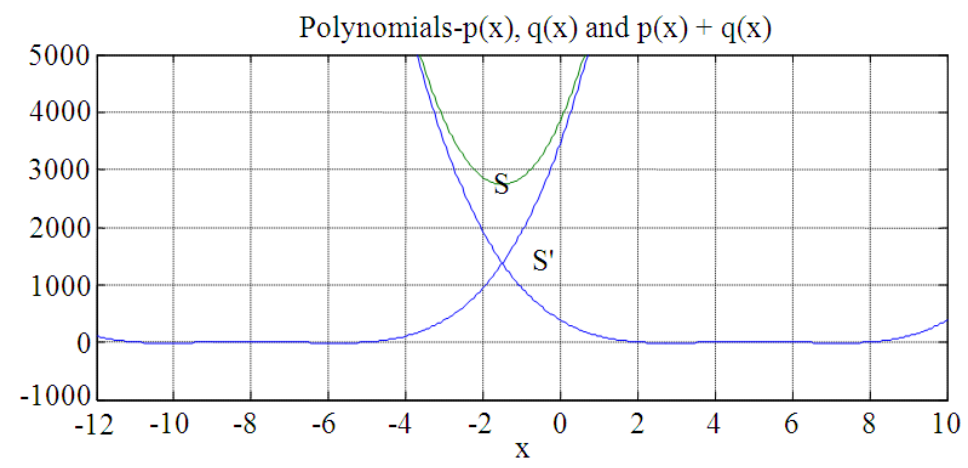

Fig. 1. Two polynomials with different roots added to form a third polynomial, $p(x)=(x+5)(x+7)(x+9)(x+11) q(x)=(x-2)(x-4)$ $(\mathrm{x}-6) ; \mathrm{w}(\mathrm{x})=\mathrm{p}(\mathrm{x})+\mathrm{q}(\mathrm{x})=2 \mathrm{x}^{4}+12 \mathrm{x}^{3}+514 \mathrm{x}^{2}+1488 \mathrm{x}+3849$

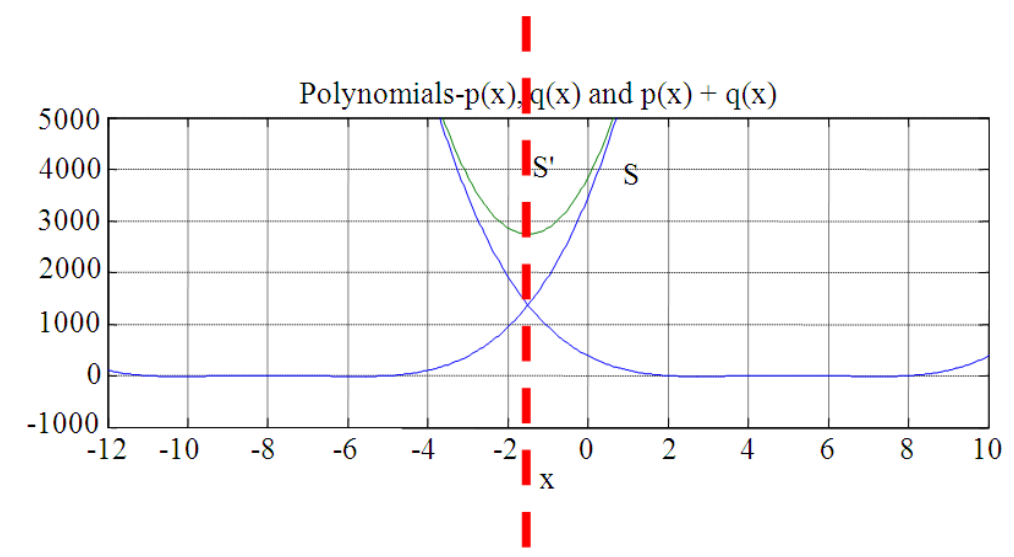

Fig. 2. Two polynomials with different roots added to form a third polynomial, $S$ ' depicts intersection point for $p(x)$ and $q(x)$ and $S$

$$
\mathrm{p}(\mathrm{x})=(\mathrm{x}+5)(\mathrm{x}+7)(\mathrm{x}+9)(\mathrm{x}+11), \quad \mathrm{q}(\mathrm{x})
$$

depicts the turning point for $\mathrm{w}(\mathrm{x})=\mathrm{p}(\mathrm{x})+\mathrm{q}(\mathrm{x})$ : $=(\mathrm{x}-2)(\mathrm{x}-4)(\mathrm{x}-6)(\mathrm{x}-8)$ and

$$
\mathrm{p}(\mathrm{x})+\mathrm{q}(\mathrm{x})=2 \mathrm{x}^{4}+12 \mathrm{x}^{3}+514 \mathrm{x}^{2}+1488 \mathrm{x}+3849
$$

For the case where $\mathrm{p}\left(\mathrm{x}_{\mathrm{s}}+\mathrm{d}\right)+\mathrm{q}\left(\mathrm{x}_{\mathrm{s}}+\mathrm{d}\right)>2 \mathrm{p}\left(\mathrm{x}_{\mathrm{s}}\right)$ for all real values of $d$ the resulting polynomial will have a singular turning point at the minimum value $\mathrm{w}\left(\mathrm{x}_{\mathrm{s}}\right)$. Importantly, if $\mathrm{w}\left(\mathrm{x}_{\mathrm{s}}\right)>0$ the solutions top $(\mathrm{x})+\mathrm{q}(\mathrm{x})$ will be of the form $x_{s}+i \beta_{j}$ for $j=1,2,3,4, \ldots, n$ (where $\beta j \in \mathfrak{R}$ ).

\section{Proof of Theorem 1:}

The difficulty in determining if the third case is the one that occurs becomes simple if the two polynomials are shifted so that the axis of symmetry aligns itself with the $\mathrm{y}$ axis. Therefore there is a need to define two new transformed polynomials such as $\mathrm{P}(\mathrm{x})$ and $\mathrm{Q}(\mathrm{x})$ :

$$
\begin{aligned}
& Q(x)=q\left(x+x_{s}\right)=\left(x+x_{s}+m_{1}\right)\left(x+x_{s}+m_{2}\right)\left(x+x_{s}+m_{3}\right) \\
& \cdots\left(x+x_{s}+m_{n}\right)=\left(x+r_{1}\right)\left(x+r_{2}\right)\left(x+r_{3}\right) \cdots\left(x+r_{n}\right)
\end{aligned}
$$

where, $r_{j}>0$ for $j=1,2,3,4, \ldots, n$ because $m_{j}>0$ for $j=$ $1,2,3,4, \ldots, n$ and $x_{\mathrm{s}}>-\mathrm{m}_{1}$ from $\mathrm{x}_{\mathrm{s}}+\mathrm{m}_{1}>0$. Upon expanding $\mathrm{Q}(\mathrm{x})$ the following form of $\mathrm{Q}(\mathrm{x})$ is obtained:

$$
\mathrm{Q}(\mathrm{x})=\mathrm{x}^{\mathrm{n}}+\mathrm{A}_{\mathrm{n}-1} \mathrm{x}^{\mathrm{n}-1}+\cdots+\mathrm{A}_{1} \mathrm{x}+\mathrm{A}_{0}
$$

where, $A_{j}>0$ for $=1,2,3,4, \ldots, n-1$. This is because each $A_{j}$ value is simply a product of a combination of $r_{j}$ values that are all positive, therefore all $\mathrm{A}_{\mathrm{j}}$ values will also be positive. This leads to an important discovery for $\mathrm{x}<0$ (i.e., $x<0$ and so $x=-d$, for $d>0$ ):

1. For even $n$ :

$$
\mathrm{Q}(-\mathrm{d})=\mathrm{d}^{\mathrm{n}}-\mathrm{A}_{\mathrm{n}-1} \mathrm{~d}^{\mathrm{n}-1}+\cdots-\mathrm{A}_{1} \mathrm{~d}+\mathrm{A}_{0}
$$


And where, $\mathrm{x}=|-\mathrm{d}|$ :

$$
\mathrm{Q}(|-\mathrm{d}|)=\mathrm{Q}(\mathrm{d})=\mathrm{d}^{\mathrm{n}}+\mathrm{A}_{\mathrm{n}-1} \mathrm{~d}^{\mathrm{n}-1}+\cdots+\mathrm{A}_{1} \mathrm{~d}+\mathrm{A}_{0}
$$

The axis of symmetry occurs for $\mathrm{P}(0)$ and $\mathrm{Q}(0)$ and the fact that the axis of symmetry is at the $y$ axis, $Q(-x)=P(x)$ :

$$
\begin{aligned}
& \mathrm{Q}(0)=(0)^{\mathrm{n}}+\mathrm{A}_{\mathrm{n}-1}(0)^{\mathrm{n}-1}+\cdots+\mathrm{A}_{1}(0)+\mathrm{A}_{0}=\mathrm{A}_{0} \\
& \mathrm{P}(\mathrm{d})+\mathrm{Q}(\mathrm{d})>2 \mathrm{Q}(0) \mathrm{Q}(-\mathrm{d})+\mathrm{Q}(\mathrm{d})>2 \mathrm{Q}(0) \\
& \mathrm{Q}(-\mathrm{d})-\mathrm{Q}(0)>\mathrm{Q}(0)-\mathrm{Q}(\mathrm{d}) 2 \mathrm{~d}^{\mathrm{n}}+\sum_{\mathrm{i}=1}^{\frac{\mathrm{n}}{2}-1} 2 \mathrm{~A}_{2 \mathrm{i}} \mathrm{d}^{2 \mathrm{i}}>0
\end{aligned}
$$

Since $A_{j}>0$ and $d>0$, Equation (2) is true for even values of $\mathrm{n}$. This also means that $\mathrm{P}(\mathrm{d})+\mathrm{Q}(\mathrm{d})>2 \mathrm{Q}(0)$ and hence $p\left(x_{s}+d\right)+q\left(x_{s}+d\right)>2 p\left(x_{s}\right)$ for even values of $n$.

2. For odd $n$ :

$\mathrm{Q}(-\mathrm{d})=-\mathrm{d}^{\mathrm{n}}+\mathrm{A}_{\mathrm{n}-1} \mathrm{~d}^{\mathrm{n}-1}-\cdots-\mathrm{A}_{1} \mathrm{~d}+\mathrm{A}_{0}$

And where $\mathrm{x}=|-\mathrm{d}|$ :

$$
\mathrm{Q}(|-\mathrm{d}|)=\mathrm{Q}(\mathrm{d})=\mathrm{d}^{\mathrm{n}}+\mathrm{A}_{\mathrm{n}-1} \mathrm{~d}^{\mathrm{n}-1}+\cdots+\mathrm{A}_{1} \mathrm{~d}+\mathrm{A}_{0}
$$

Since the axis of symmetry occurs for $\mathrm{P}(0)$ and $\mathrm{Q}(0)$ (at the $y$ axis), $\mathrm{Q}(-\mathrm{x})=\mathrm{P}(\mathrm{x})$ :

$$
\begin{aligned}
& \mathrm{Q}(0)=(0)^{\mathrm{n}}+\mathrm{A}_{\mathrm{n}-1}(0)^{\mathrm{n}-1}+\cdots+\mathrm{A}_{1}(0)+\mathrm{A}_{0}=\mathrm{A}_{0} \\
& \mathrm{P}(\mathrm{d})+\mathrm{Q}(\mathrm{d})>2 \mathrm{Q}(0) \mathrm{Q}(-\mathrm{d})+\mathrm{Q}(\mathrm{d})>2 \mathrm{Q}(0) \\
& \mathrm{Q}(-\mathrm{d})-\mathrm{Q}(0)>\mathrm{Q}(0)-\mathrm{Q}(\mathrm{d}) \sum_{\mathrm{i}=1}^{\frac{\mathrm{n}-1}{2}} 2 \mathrm{~A}_{2 \mathrm{i}} \mathrm{d}^{2 \mathrm{i}}>0
\end{aligned}
$$

Since $A_{j}>0$ and $d>0$, Equation (3) is true for odd $n$ values and this means that $\mathrm{P}(\mathrm{d})+\mathrm{Q}(\mathrm{d})>2 \mathrm{Q}(0)$ and hence $\mathrm{p}\left(\mathrm{x}_{\mathrm{s}}+\mathrm{d}\right)+\mathrm{q}\left(\mathrm{x}_{\mathrm{s}}+\mathrm{d}\right)>2 \mathrm{p}\left(\mathrm{x}_{\mathrm{s}}\right)$ for all odd $\mathrm{n}$. Finally, this means that $\mathrm{w}\left(\mathrm{x}_{\mathrm{s}}+\mathrm{d}\right)>\mathrm{w}\left(\mathrm{x}_{\mathrm{s}}\right)$ for $\mathrm{d}>0$ and all $\mathrm{n}$ values. Therefore, the resulting polynomial will have a singular turning point at the minimum value: $\mathrm{w}\left(\mathrm{x}_{\mathrm{s}}\right)$. This is an important case because if $\mathrm{w}\left(\mathrm{x}_{\mathrm{s}}\right)>0$ the solutions to $\mathrm{w}\left(\mathrm{x}_{\mathrm{s}}\right)$ $=0$ will be of the form $x_{s}+i \beta_{j}$ for $j=1,2,3,4, \ldots, n$ (where $\beta_{\mathrm{j}} \in \mathfrak{R}$ ).

To prove $\mathrm{w}\left(\mathrm{x}_{\mathrm{s}}\right)>0$, the $\mathrm{q}(\mathrm{x})$ polynomial will is translated by shifting the polynomial to the right by a value of $-m_{1}$. This allows for $m_{1}=0$ :

$$
\begin{aligned}
& \mathrm{Q}(\mathrm{x})=\mathrm{q}\left(\mathrm{x}-\mathrm{m}_{1}\right)=\left(\mathrm{x}-\mathrm{m}_{1}+\mathrm{m}_{1}\right)\left(\mathrm{x}-\mathrm{m}_{1}+\mathrm{m}_{2}\right)\left(\mathrm{x}-\mathrm{m}_{1}+\mathrm{m}_{3}\right) \\
& \cdots\left(\mathrm{x}-\mathrm{m}_{1}+\mathrm{m}_{\mathrm{n}}\right)=(\mathrm{x})\left(\mathrm{x}+\mathrm{s}_{1}\right)\left(\mathrm{x}+\mathrm{s}_{2}\right) \cdots\left(\mathrm{x}+\mathrm{s}_{\mathrm{n}-1}\right)
\end{aligned}
$$

where, $s_{j}>0$ for $\mathrm{j}=1,2,3,4, \ldots, n-1$, because $\left|m_{j}\right|<\left|m_{j+1}\right|$ for $\mathrm{j}=1,2,3,4, \ldots, \mathrm{n}-1$. Expanding $\mathrm{Q}(\mathrm{x})$ leads to:

$$
\begin{aligned}
& \mathrm{Q}(\mathrm{x})=(\mathrm{x})\left(\mathrm{x}+\mathrm{s}_{1}\right)\left(\mathrm{x}+\mathrm{s}_{2}\right) \ldots\left(\mathrm{x}+\mathrm{S}_{\mathrm{n}-1}\right) \Rightarrow> \\
& \mathrm{Q}(\mathrm{x})=\mathrm{x}^{\mathrm{n}}+\mathrm{B}_{\mathrm{n}-1} \mathrm{x}^{\mathrm{n}-1}+\cdots+\mathrm{B}_{1} \mathrm{x}+\mathrm{B}_{0}
\end{aligned}
$$

where, $B_{j}>0$ for $j=1,2,3,4, \ldots, n-1$, because each $B_{j}$ is simply a product of a combination of $\mathrm{s}_{\mathrm{j}}$, which are positive; therefore $B_{j}$ will also be positive for all $\mathrm{j}$. This means that $\mathrm{Q}(\mathrm{x})>0$ for $\mathrm{x}>0$. Hence, if $\mathrm{Q}(\mathrm{x})>0$ for $\mathrm{x}>0$ then $\mathrm{Q}\left(\mathrm{x}+\mathrm{m}_{1}\right)>0$ for $\mathrm{x}>-\mathrm{m}_{1}$ :

$$
\begin{aligned}
& \mathrm{Q}\left(\mathrm{x}+\mathrm{m}_{1}\right)=\left(\mathrm{x}+\mathrm{m}_{1}\right)\left(\mathrm{x}+\mathrm{m}_{1}+\mathrm{s}_{1}\right)\left(\mathrm{x}+\mathrm{m}_{1}+\mathrm{s}_{2}\right) \ldots\left(\mathrm{x}+\mathrm{m}_{1}\right. \\
& \left.+\mathrm{S}_{\mathrm{n}-1}\right)=\left(\mathrm{x}+\mathrm{m}_{1}\right)\left(\mathrm{x}+\mathrm{m}_{2}\right)\left(\mathrm{x}+\mathrm{m}_{3}\right) \cdots\left(\mathrm{x}+\mathrm{m}_{\mathrm{n}}\right)=\mathrm{q}(\mathrm{x})
\end{aligned}
$$

This means $\mathrm{q}(\mathrm{x})>0$ for $\mathrm{x}>-\mathrm{m}_{1}$. By definition $\mathrm{x}_{\mathrm{s}}>-$ $\mathrm{m}_{1}$ that implies $\mathrm{q}\left(\mathrm{x}_{\mathrm{s}}\right)>0$. Using $\mathrm{w}\left(\mathrm{x}_{\mathrm{s}}\right)=2 \mathrm{q}\left(\mathrm{x}_{\mathrm{s}}\right)$ leads to the condition that $\mathrm{w}\left(\mathrm{x}_{\mathrm{s}}\right)>0$. The above proves theorem 1 .

\section{Summary of Theorem 1:}

Defining $\mathrm{p}(\mathrm{x})$ and $\mathrm{q}(\mathrm{x})$ as the polynomials governed by the conditions and the proofs set out in the previous section leads to the following theorem;

The sum of two polynomials $\mathrm{p}(\mathrm{x})$ and $\mathrm{q}(\mathrm{x})$ under certain conditions will result in a polynomial that has solutions (i.e. roots) of the form $a+i \beta_{j}$ for $j=$ $1,2,3,4, \ldots, \mathrm{n}\left(\beta_{\mathrm{j}} \in \mathfrak{R}\right)$.

\subsection{Application of Theorem 1: Application to the Riemann Hypothesis}

The Riemann hypothesis deals with the functional equation of the following form Curtis and Tularam (2011):

$$
\prod\left(\frac{\mathrm{s}}{2}-1\right)(\pi)^{-\frac{\mathrm{s}}{2}}(\zeta(\mathrm{s}))=\prod\left(\frac{1-\mathrm{s}}{2}-1\right)(\pi)^{-\frac{1-\mathrm{s}}{2}}(\zeta(1-\mathrm{s}))
$$

Since there are a number of different proofs of this equation the derivation or proof will be left up to the readers. Riemann used the functional equation above to define an analytic function that is defined for all values of s. Another form of Riemann's original function more commonly used is given in Equation (4):

$\xi(\mathrm{s})=\prod\left(\frac{\mathrm{s}}{2}\right)(\mathrm{s}-1)(\pi)^{-\frac{\mathrm{s}}{2}}(\zeta(\mathrm{s}))$ 
Riemann derived an equation (Equation 5) for $\xi(\mathrm{s})$ to determine values of that would firstly solve $\xi(\mathrm{s})=0$; and $\varsigma(\mathrm{s})=0$ then, (Edwards, 2001):

$\xi(s)=\frac{1}{2}-\frac{s(1-s)}{2} \int_{1}^{\infty} \psi(x)\left(x^{\frac{s}{2}-1}+x^{-\frac{s+1}{2}}\right) d x$

where, $\Psi(\mathrm{x})=\sum_{\mathrm{n}=1}^{00} \mathrm{e}^{\left(-\pi \mathrm{n}^{2} \mathrm{x}\right)}$

The integral in Equation (5) can be evaluated using integration by parts method to arrive at a function for $\xi(\mathrm{s})$. It is well known that the real part for each solution to $\xi(\mathrm{s})=0$ lie in the region $0 \leq \operatorname{Re}(\xi(\mathrm{s})) \leq 1$ with the exception of the trivial poles and the two poles at $\mathrm{s}=1$ and $\mathrm{s}=0$ (Edwards, 2001). The objective of this section of the study is to evaluate Equation (5) in the same fashion as Riemann's original idea but in reverse and continually. That is to evaluate the integral part within Equation (5) repeatedly to define a variety of expressions that can be governed by Theorem 1. A number of functions presented below are important for the process:

$$
\begin{gathered}
\Psi_{1}(\mathrm{x})=\int_{1}^{\infty} \sum_{\mathrm{n}=1}^{\infty} \mathrm{e}^{-\pi \mathrm{n}^{2} \mathrm{x}} \mathrm{dx}=\sum_{\mathrm{n}=1}^{\infty} \frac{(-1)^{1}}{\pi \mathrm{i}^{2}} \mathrm{e}^{-\pi \mathrm{n}^{2} \mathrm{x}} \\
\Psi_{2}(\mathrm{x})=\int_{1}^{\infty} \Psi_{1}(\mathrm{x}) \mathrm{d} \mathrm{x}=\sum_{\mathrm{n}=1}^{\infty} \frac{(-1)^{2}}{\pi^{2} \mathrm{i}^{4}} \mathrm{e}^{-\pi \mathrm{n}^{2} \mathrm{x}} \\
\psi_{3}(\mathrm{x})=\int_{1}^{\infty} \Psi_{2}(\mathrm{x}) \mathrm{dx}=\sum_{\mathrm{n}=1}^{\infty} \frac{(-1)^{3}}{\pi^{3} \mathrm{i}^{6}} \mathrm{e}^{-\pi \mathrm{n}^{2} \mathrm{x}} \text { and } \\
\Psi_{\mathrm{n}}(\mathrm{x})=\int_{1}^{\infty} \Psi_{\mathrm{n}-1}(\mathrm{x}) \mathrm{dx}=\sum_{\mathrm{n}=1}^{\infty} \frac{(-1)^{\mathrm{n}}}{\pi^{\mathrm{n}^{2 n}} \mathrm{e}^{-\pi \mathrm{n}^{2} \mathrm{x}}}
\end{gathered}
$$

where, $\Psi_{\mathrm{k}}$ (s) has a convergent summation for all $\mathrm{k}$ (Edwards, 2001). Allowing the integral to be passed within the summation itself and evaluating the exponential function leads to the following.

First evaluation of Equation (5):

$$
\begin{aligned}
& \xi(\mathrm{s})=\frac{1}{2}-\frac{1}{2} \mathrm{~s}(1-\mathrm{s})\left[\left.\Psi_{1}(\mathrm{x})\left(\mathrm{x}^{\frac{1}{2}(\mathrm{~s}-2)}+\mathrm{x}^{-\frac{1}{2}(\mathrm{~s}+1)}\right)\right|_{1} ^{\infty}\right] \\
& -\frac{1}{2} \mathrm{~s}(1-\mathrm{s})\left[-\frac{1}{2} \int_{1}^{\infty} \Psi_{1}(\mathrm{x})\left((\mathrm{s}-2) \mathrm{x}^{\frac{1}{2}(\mathrm{~s}-4)}+(-(\mathrm{s}+1)) \mathrm{x}^{-\frac{1}{2}(\mathrm{~s}+3)}\right) \mathrm{dx}\right]
\end{aligned}
$$

while the $\mathrm{k}^{\text {th }}$ (even) evaluation:

$$
\begin{aligned}
& \xi(s)=\frac{1}{2}-\frac{1}{2} s(1-s)\left[\left.\psi_{1}(x)\left(x^{\frac{1}{2}(s-2)}+x^{-\frac{1}{2}(s+1)}\right)\right|_{1} ^{\infty}\right. \\
& +\sum_{j=2}^{k}\left(\left(\begin{array}{l}
\left.\left.\frac{(-1)^{j-1}}{2^{j-1}} \psi_{j}(x)\left(\left(\prod_{m=1}^{j-1}(s-2 m)\right) x^{\frac{1}{2}(s-2 j)}+\right)^{\infty}(-(s+(2 m-1)))\right) x^{-\frac{1}{2}(s+(2 j-1))}\right) \\
m^{-1}
\end{array}\right)\right. \\
& +\frac{1}{2^{k}} \int_{1}^{\infty} \psi_{k}(x)\left(\begin{array}{l}
\left(\prod_{m=1}^{k}(s-2 m)\right) x^{\frac{1}{2}(s-2(k+1))} \\
+\left(\prod_{m=1}^{k}(-(s+(2 m-1)))\right) x^{-\frac{1}{2}(s+2 k+1)}
\end{array}\right) d x
\end{aligned}
$$

$\mathrm{k}+1^{\text {th }}$ (odd) evaluation:

$$
\begin{aligned}
& \xi(\mathrm{s})=\frac{1}{2}-\frac{1}{2} \mathrm{~s}(1-\mathrm{s})\left[\left.\psi_{1}(\mathrm{x})\left(\mathrm{x}^{\frac{1}{2}(\mathrm{~s}-2)}+\mathrm{x}^{-\frac{1}{2}(\mathrm{~s}+1)}\right)\right|_{1} ^{\infty}\right.
\end{aligned}
$$

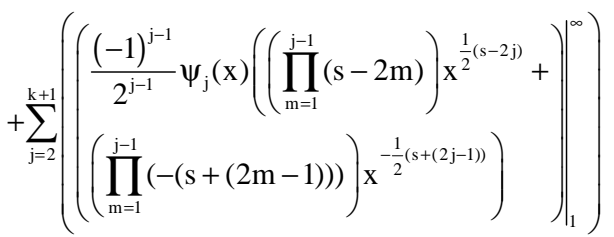

$$
\begin{aligned}
& \left.+\frac{1}{2^{k+1}} \int_{1}^{\infty} \psi_{k+1}(\mathrm{x})\left(\begin{array}{l}
\left(\prod_{\mathrm{m}=1}^{k+1}(\mathrm{~s}-2 \mathrm{~m})\right) \mathrm{x}^{\frac{1}{2}(s-2(k+2))} \\
+\left(\prod_{\mathrm{m}=1}^{k+1}(-(\mathrm{s}+(2 \mathrm{~m}-1)))\right) \mathrm{x}^{-\frac{1}{2}(s+2 k+3)}
\end{array}\right) \mathrm{dx}\right]
\end{aligned}
$$

Therefore the $\mathrm{n}^{\text {th }}$ (even) evaluation:

$$
\begin{aligned}
& \xi(s)=\frac{1}{2}-\frac{1}{2} s(1-s)\left[\left.\psi_{1}(x)\left(x^{\frac{1}{2}(s-2)}+x^{-\frac{1}{2}(s+1)}\right)\right|_{1} ^{\infty}\right. \\
& +\sum_{j=2}^{n}\left(\left(\begin{array}{l}
\left.\frac{(-1)^{j-1}}{2^{j-1}} \psi_{j}(x)\left(\left(\prod_{m=1}^{j-1}(s-2 m)\right) x^{\frac{1}{2}(s-2 j)}+\left.\right|_{m=1} ^{\infty}(-(s+(2 m-1)))\right) x^{-\frac{1}{2}(s+(2 j-1))}\right) \\
\prod^{\infty}
\end{array}\right)\right. \\
& +\frac{1}{2^{n}} \int_{1}^{\infty} \psi_{n}(x)\left(\begin{array}{l}
\left(\prod_{m=1}^{n}(s-2 m)\right) x^{\frac{1}{2}(s-2(n+1))} \\
+\left(\prod_{m=1}^{n}(-(s+(2 m-1)))\right) x^{-\frac{1}{2}(s+2 n+1)}
\end{array}\right) d x
\end{aligned}
$$

Noting that an arbitrary $1^{\text {th }}$ term can be represented as: 


$$
\begin{aligned}
& \left.\psi_{1}(\mathrm{x})\left(\prod_{\mathrm{m}=1}^{1-1}(\mathrm{~s}-2 \mathrm{~m}) \mathrm{x}^{\frac{1}{2}(\mathrm{~s}-21)}+\prod_{\mathrm{m}=1}^{1-1}(-(\mathrm{s}+(2 \mathrm{~m}-1))) \mathrm{x}^{-\frac{1}{2}(\mathrm{~s}+21-1)}\right)\right|_{1} ^{\infty} \\
& =-\psi_{1}(1)\left(\prod_{\mathrm{m}=1}^{1-1}(\mathrm{~s}-2 \mathrm{~m})+\prod_{\mathrm{m}=1}^{1-1}(-(\mathrm{s}+(2 \mathrm{~m}-1)))\right)
\end{aligned}
$$

$\Psi_{1}(\infty)$ converges rapidly to zero for $\mathrm{I} \geq 1$ even when compared with any power of $x$ function (Edwards, 2001). Therefore, defining Equation (6) as follows aids the process:

$$
\begin{aligned}
& \xi(\mathrm{s})=\frac{1}{2}-\frac{1}{2} \mathrm{~s}(1-\mathrm{s}) \\
& {\left[-\psi_{1}(1)+\sum_{\mathrm{j}=2}^{\mathrm{n}-1}\left(\frac{(-1)^{\mathrm{j}}}{2^{\mathrm{j}-1}} \psi_{\mathrm{j}}(1)\left(\prod_{\mathrm{m}=1}^{\mathrm{j}-1}(\mathrm{~s}-2 \mathrm{~m})+\prod_{\mathrm{m}=1}^{\mathrm{j}-1}(-(\mathrm{s}+(2 \mathrm{~m}-1)))\right)\right)\right.} \\
& +\frac{1}{2^{\mathrm{n}}} \int_{1}^{\infty} \psi_{\mathrm{n}}(\mathrm{x})\left(\begin{array}{l}
\left(\prod_{\mathrm{m}=1}^{\mathrm{n}}(\mathrm{s}-2 \mathrm{~m})\right) \mathrm{x}^{\frac{1}{2}(\mathrm{~s}-2(\mathrm{n}+1))} \\
+\left(\prod_{\mathrm{m}=1}^{\mathrm{n}}(-(\mathrm{s}+(2 \mathrm{~m}-1)))\right) \mathrm{x}^{-\frac{1}{2}(\mathrm{~s}+2 \mathrm{n}+1)}
\end{array}\right) \mathrm{dx}
\end{aligned}
$$

Also, defining Equation (7):

$$
g(s)=\frac{1}{2}-\frac{1}{2} s(1-s)\left[-\psi_{1}(1)+\sum_{j=2}^{n}\left(\begin{array}{l}
\frac{(-1)^{j}}{2^{j-1}} \psi_{j}(1) \\
\left(\prod_{m=1}^{j-1}(s-2 m)+\right. \\
\left.\prod_{m=1}^{j-1}(-(s+(2 m-1)))\right)
\end{array}\right)\right]
$$

Rearranging for simplicity leads to the following Equation 7.1:

$$
\begin{aligned}
& g(s)=\frac{1}{2}-\frac{1}{2} s(1-s)\left[-\left(\psi_{1}(1)+\frac{3}{2} \psi_{2}(1)\right)\right. \\
& \left.+\sum_{j=3}^{n}\left(\begin{array}{l}
\frac{(-1)^{j}}{2^{j-1}} \psi_{j}(1) \\
\left(\prod_{m=1}^{j-1}(s-2 m)+\prod_{m=1}^{j-1}(-1)(s+(2 m-1))\right)
\end{array}\right)\right]
\end{aligned}
$$

Essentially, Equation 7.1 includes polynomial terms that are governed by Theorem 1. The terms in Equation 7.1 that include even degree polynomials will be the first focus of applying Theorem 1. Assuming $\mathrm{n}$ to be even the following may be written:

$$
\begin{aligned}
& \mathrm{p}(\mathrm{s})=\prod_{\mathrm{m}=1}^{\mathrm{n}}(\mathrm{s}-2 \mathrm{~m}) \\
& \mathrm{q}(\mathrm{s})=\prod_{\mathrm{m}=1}^{\mathrm{n}}(\mathrm{s}+(2 \mathrm{~m}-1))
\end{aligned}
$$

It is now necessary to show that Equation (8 and 9) can be expressed in the manner shown in Equation (1): That will prove that Theorem 1 can be applied $\left(\mathrm{s}_{\mathrm{s}}\right.$ will simply be the s value where the axis of symmetry occurs). This value s will represent some constant.

It should be noted that both $\mathrm{p}(\mathrm{s})$ and $\mathrm{q}(\mathrm{s})$ are even degree polynomials with $\mathrm{n}$ real roots and so will have an even degree of product terms when in factored form:

$$
\therefore \mathrm{p}(\mathrm{s})=\prod_{\mathrm{m}=1}^{\mathrm{n}}(\mathrm{s}-2 \mathrm{~m})=\prod_{\mathrm{m}=1}^{\mathrm{n}}(2 \mathrm{~m}-\mathrm{s})
$$

Now substituting in: -(s-1) for all $\mathrm{s}$ values into $\mathrm{p}(\mathrm{s})$ :

$$
\begin{aligned}
& \mathrm{p}(-(\mathrm{s}-1))=\prod_{\mathrm{m}=1}^{\mathrm{n}}(2 \mathrm{~m}-(-(\mathrm{s}-1))) \\
& =\prod_{\mathrm{m}=1}^{\mathrm{n}}(2 \mathrm{~m}+\mathrm{s}-1)=\prod_{\mathrm{m}=1}^{\mathrm{n}}(\mathrm{s}+(2 \mathrm{~m}-1))=\mathrm{q}(\mathrm{s})
\end{aligned}
$$

Noting that this is Equation (1) where $s=1 / 2$ thus Theorem 1 may now be applied to the terms in Equation 7.1 that include even degree polynomials. The resulting polynomials will be of the following form:

$$
\mathrm{w}(\mathrm{s})=\prod_{\mathrm{m}=1}^{\mathrm{n}}\left(\mathrm{s}-\frac{1}{2}+\mathrm{i} \beta_{\mathrm{m}}\right)
$$

These resulting polynomials all have solutions to $\mathrm{w}(\mathrm{s})=0$ that will lie on the real line: $\mathrm{s}=1 / 2$.

The same process will now be applied to the terms in Equation (7.1) that include odd degree polynomials. Considering $\mathrm{n}$ to be odd the following may be written Equation (10 and 11):

$$
\begin{aligned}
& \mathrm{p}(\mathrm{s})=\prod_{\mathrm{m}=1}^{\mathrm{n}}(\mathrm{s}-2 \mathrm{~m}) \\
& \mathrm{q}(\mathrm{s})=\prod_{\mathrm{m}=1}^{\mathrm{n}}(\mathrm{s}+(2 \mathrm{~m}-1))
\end{aligned}
$$

Equation (7.1) shows that all the terms with odd degree polynomials will be of the general form; $\mathrm{C}(\mathrm{p}(\mathrm{s})-\mathrm{q}(\mathrm{s}))$, where $\mathrm{C}$ is simply the constant represented in Equation 
(7.1). In the case where $\mathrm{p}(\mathrm{s})$ and $\mathrm{q}(\mathrm{s})$ are both odd degree polynomials with $\mathrm{n}$ real roots, there will be an odd degree of product terms when in factored form such as:

$$
\therefore \mathrm{p}(\mathrm{s})=\prod_{\mathrm{m}=1}^{\mathrm{n}}(\mathrm{s}-2 \mathrm{~m})=-\prod_{\mathrm{m}=1}^{\mathrm{n}}(2 \mathrm{~m}-\mathrm{s})
$$

Finally we need to show that:- $q(s)=p\left(-\left(s-2 s_{s}\right)\right)$ to prove Theorem 1 can be applied.

Substituting in: $-(\mathrm{s}-1)$ for all $\mathrm{s}$ values into $\mathrm{p}(\mathrm{s})$ gives:

$$
\begin{aligned}
& \mathrm{p}(-(\mathrm{s}-1))=-\prod_{\mathrm{m}=1}^{\mathrm{n}}(2 \mathrm{~m}-(-(\mathrm{s}-1)))= \\
& -\prod_{\mathrm{m}=1}^{\mathrm{n}}(2 \mathrm{~m}+\mathrm{s}-1)=-\prod_{\mathrm{m}=1}^{\mathrm{n}}(\mathrm{s}+(2 \mathrm{~m}-1))=-\mathrm{q}(\mathrm{s})
\end{aligned}
$$

Therefore, the general forms of the odd degree polynomial terms in Equation (7.1) become:

$$
\mathrm{C}(\mathrm{p}(\mathrm{s})+\mathrm{p}(-(\mathrm{s}-1)))
$$

That is simply the addition of two polynomials, under the conditions prescribed in Theorem 1. Applying Theorem 1 where $s=1 / 2$ from Equation (1), the terms in Equation (7.1) that include odd degree polynomials will result in a polynomial whose general form is $\mathrm{w}(\mathrm{s})$ :

$$
\mathrm{w}(\mathrm{s})=\prod_{\mathrm{m}=1}^{\mathrm{n}}\left(\mathrm{s}-\frac{1}{2}+\mathrm{i} \beta_{\mathrm{m}}\right)
$$

$\mathrm{W}(\mathrm{s})=0$ has all its solutions that will lie on the real line $s=1 / 2$.

There have been numerous successful and unsuccessful studies in the effort in proving Riemann's hypothesis but very little work has been done in regards to why the hypothesis should or should not be true; this study is a step forward in this regard by suggesting that there may be a sound reason why the Riemann hypothesis should be correct.

The above application of Theorem 1 to the Riemann hypothesis merely allows for a new look at Riemann's eta function. It has simplified Equation 7.1 in such a way that the terms, excluding the first term $1 / 2$, are now polynomials of increasing degree with rather interesting solutions when set to zero. The multiplying factor of $1 / 2 \mathrm{~s}(1-\mathrm{s})$ means that each polynomial term will have two solutions when set to zero, $s=0$ and $s=1$. All other solutions if any exist will lie on the real line of $1 / 2$. This is closely related to Riemann's original hypothesis where the zeta functions solutions when set to zero will all lie on the real line of $1 / 2$.

\section{CONCLUSION}

The arguments presented in this study provides very sound basis to conclude that the Riemann Hypothesis is true. There are a number of implications that will develop this idea more generally. For example, assuming the integral term and first term 1/2. of Equation 6 can be ignored, based on Theorem 1, all that is left are polynomial terms of increasing degree. Then if we go further by making the assumption that summing two polynomials of any degree where both polynomials have roots that lie on the real line of $1 / 2$., results in a polynomial whose roots also lie on the real line of $1 / 2$. will help simplify Equation 6 into a single polynomial with all its roots lying on the real line of $1 / 2$.. The final assumption is that the resulting polynomial can be taken to an 'infinite' degree. Making these four assumptions will result in a polynomial of infinite degree whose roots (excluding the trivial roots) all lie on the real line of $1 / 2$.. This is where the arguments and theorem of this study can be taken but this was not the overall aim of the study. The aim was to provide sound reasons why the Riemann hypothesis should be correct. The simplification of the integral form of the eta function using the new theorem on the summation of two polynomials has done just that.

\section{REFERENCES}

Agarwal, P., A. Jain and M. Chand, 2012. Solutions of higher-degree reduced polynomial equations by using unipodalnumbers. Theor. Math. Appli., 2: 13-21. 6

Brenner, J.L. and R.C. Lyndon, 1981. Proof of the fundamental theorem of algebra. Am. Math. Mon., 4: 253-256. DOI: $10.2307 / 2320547$

Curtis, M. and G.A. Tularam, 2011. The importance of numbers and the need to study primes: The prime questions. J. Math. Stat., 7: 262-269. DOI: 10.3844/jmssp.2011.262.269

Edwards, H.M., 2001. Riemann's Zeta Function, Dover Publications. 1st Edn., Courier Dover Publications, New York, ISBN-10: 0486428133, pp: 517.

Titchmarsh, E.C., 1986. The Theory of the Riemann Zeta-Function. 1st Edn., Oxford University Press, New York, ISBN-10: 0198533691, pp: 412.

Tularam, G.A., 2011. Investigating the development of arithmetic and algebra in vedic india. Int. J. Math., 20: $1-25$.

Tularam, G.A., 2013. Arithmetic and algebra in Vedic India: Tribute to Swami Dayananda Saraswati. In: Mathematics, Game Theory and Algebra Compendium, Malthius, J. (Ed.), NOVA Science, New York, ISBN-10: 1622577493, pp: 163-184. 